\title{
Molecular Cloning, Protein Expression, and Regulatory Mechanisms of the Chitinase Gene from Spodoptera littoralis Nucleopolyhedrovirus
}

\author{
Norhan Yasser ${ }^{1}$, Reda Salem ${ }^{1}$, Maha Alkhazindar ${ }^{2}$, Ismail A. Abdelhamid ${ }^{2}$, Said A. S. Ghozlan ${ }^{2}$, and Wael Elmenofy ${ }^{1 *}$ \\ ${ }^{1}$ Agricultural Genetic Engineering Research Institute, ARC, Giza 12619, Egypt \\ ${ }^{2}$ Faculty of Science, Cairo University, Giza 12619, Egypt
}

Received: April 5, 2021 / Revised: June 29, 2021 / Accepted: July 22, 2021

\begin{abstract}
The cotton leafworm, Spodoptera littoralis, is a major pest in Egypt and many countries worldwide, and causes heavy economic losses. As a result, management measures to control the spread of the worm are required. S. littoralis nucleopolyhedrovirus (SpliNPV) is one of the most promising bioagents for the efficient control of insect pests. In this study, a chitinase gene (chitA) of a $1.8 \mathrm{~kb}$ DNA fragment was cloned and fully characterized from SpliNPV-EG1, an Egyptian isolate. A sequence of 601 amino acids was deduced when the gene was completely sequenced with a predicted molecular mass of $67 \mathrm{kDa}$ for the preprotein. Transcriptional analyses using reverse transcription polymerase chain reaction (RT-PCR) revealed that chitA transcripts were detected first at $12 \mathrm{~h}$ post infection (hpi) and remained detectable until $168 \mathrm{hpi}$, suggesting their transcriptional regulation from a putative late promoter motif. In addition, quantitative analysis using quantitative RT-PCR showed a steady increase of 7.86 -fold at $12 \mathrm{hpi}$ in chitA transcription levels, which increased up to 71.4 -fold at $120 \mathrm{hpi}$. An approximately $50 \mathrm{kDa}$ protein fragment with chitinolytic activity was purified from ChitA-induced bacterial culture and detected by western blotting with an antirecombinant SpliNPV chitinase antibody. Moreover, purification of the expressed ChitA recombinant protein showed in vitro growth inhibition of two different fungi species, Fusarium solani and F. oxysporum, confirming that the enzyme assembly and activity was correct. The results supported the potential role and application of the SpliNPV-ChitA protein as a synergistic agent in agricultural fungal and pest control programs.
\end{abstract}

Keywords: Spodoptera littoralis NPV, chitinase gene A, qRT-PCR, protein expression, antifungal activity

\section{Introduction}

Baculoviruses, belonging to the family Baculoviridae, are a large group of viruses found naturally in the environment. They are pathogenic to arthropods, mainly insects from orders Lepidoptera, Diptera, and Hymenoptera [1]. In addition, baculoviruses have been used extensively as an effective tool for foreign protein

\section{*Corresponding author}

Tel.: +00201203212056, Fax: +00201203212056

E-mail: wael.elmenofy@ageri.sci.eg expression [2-4]. Family Baculoviridae includes insectspecific viruses with dsDNA virus genomes ranging in size from 80 to $180 \mathrm{~kb}$. Based on virus-occlusion body (OB) morphology, the family Baculoviridae is divided into two genera: nucleopolyhedrovirus (NPV) and granulovirus (GV) [5]. NPVs have large polyhedra that occlude many virions, whereas $\mathrm{GVs}$ have smaller granule-like OBs and occluding a single virion in its granulin matrix. The full nucleotide sequences of several baculovirus isolates have enhanced the extensive analysis of the viral genome component and its properties toward the effective control of insect pests [5-8]. Baculoviruses are the 
most commonly investigated insect viruses concerning their development as biological control agents due to their favorable features, such as safety to the environment, humans, other vertebrates, plants, and natural enemies of pests [9].

Chitin is the most widely recognized common polysaccharide comprising $\mathrm{N}$-acetylglucosamine subunits. It can be found in exoskeletons of crustaceans, fungi, and insects [10]. Chitin degradation is initiated by the chitinase enzyme, which plays a crucial role in chitin degradation to its monosaccharides. Chitinases are involved in plant defense mechanisms [11], breakdown activity of old cuticle in insects [12], and pathogenicity of baculovirus toward its insect hosts [13]. Chitinases are categorized into glycosyl hydrolase families 18 to 20 depending on the similarity of amino acid sequences, structure, and reaction mechanism. Chitinases of NPVs belong to the chitinase family 18 and are expressed at a late stage of viral infection, causing the liquefaction of the insect host and leading to the release of progeny virus into the environment [14].

Genes that encode chitinases are found in most baculoviral genomes that have been completely sequenced to date. Baculovirus chitinase phylogenetic analyses have shown that they are monophyletic, but the broad division between GVs and NPVs indicates that the chitinase gene was present in an ancestral virus before the two genera were isolated $[15,16]$.

The first chitinase gene (chitA) was identified from the genome of the prototype virus, Autographa californica NPV (AcNPV) [17]. In the late stage of the virus lifecycle, endochitinase and exochitinase activities were detected first at $12 \mathrm{~h}$ postinfection (hpi) with a relatively high amount. The analysis showed that the chitinase protein of AcNPV was approximately $58 \mathrm{kDa}$. In addition, the protein sequence predicted by AcNPV chitA shared substantial sequence similarity (60.5\% of the same residue) to Serratia marcescens chitinase A.

Phylogenetic analyses pointed out that AcNPV acquired the chitinase gene from a bacterium passing through horizontal gene transfer [17]. The enzyme was found associated with viral OBs (polyhedral) that are expected to be released during polyhedral dissolving in the high alkaline midgut of infected insects. This may lead to the degradation of the peritrophic membrane (PM), allowing the virus to more efficiently reach midgut epithelial cells [14]. Chitinase expression at the late phase of viral infection causes the liquefaction of the insect host, allowing the release of virus progeny into the environment [14].

The role of viral chitinase in infected larvae liquefaction is highly important, as the complete deletion of the viral chitinase gene from the viral genome fails the liquefaction of dead larvae after viral infection [18]. A Cterminal KDEL motif or its variants (XXEL) are conserved in baculovirus chitinase gene sequences. The complete knocking out of this motif or its variants results in the earlier secretion of virus-infected cells into the insect medium [19, 20].

Spodoptera littoralis NPV (SpliNPV) of the family Baculoviridae is one of the most promising biocontrol agents for the effective control of S. littoralis [21, 22]. The published genome sequence of SpliNPV allowed first insights into the genetic make-up of the virus and its coding genes in addition to its relationship to other baculoviruses [23].

This study aimed to investigate the molecular properties of chitinase gene A (chitA) from SpliNPV-EG1, an Egyptian isolate, by analyzing the phylogeny of the chitinase gene, temporal transcriptional regulation of chitA mRNA upon infection of $S$. littoralis, and in vitro protein expression profile, and determining its antifungal activity on economic plant pathogen fungi.

\section{Materials and Methods}

\section{Insect, virus, and propagation of SpliNPV}

The cotton leafworm S. littoralis (Boisd) used for virus propagation was derived from the insect rearing facility of the Agricultural Genetic Engineering Research Institute, Agricultural Research Center (ARC). The SpliNPV used in this study is a field-collected baculovirus isolate genus NPV collected from infected $S$. littoralis cadavers from Giza District in Egypt (isolate SpliNPV-EG1). Insect larvae were reared on a semiartificial diet containing agar-agar, maize meal, wheat germ, brewer's yeast, ascorbic acid, and Nipagin (hydroxybenzoic acid methyl), as described previously by Ivaldi-Sender [24]. The fourth instar of $S$. littoralis larvae was inoculated by feeding them on cubes of a semiartificial diet inoculated with $10^{5}$ OBs of SpliNPV. Only larvae that had completely ingested the medium within $24 \mathrm{~h}$ were transferred to a 
virus-free medium and reared individually at $26{ }^{\circ} \mathrm{C}$ until the observation of viral infection symptoms (7-10 days postinfection) and then collected in 1.5-ml Eppendorf tubes just after larval death and kept frozen at $-20^{\circ} \mathrm{C}$.

\section{Virus OB purification}

Infected $S$. littoralis larvae were collected and homogenized in a grinding mortar using $0.1 \%$ sodium dodecyl sulfate (SDS) and then ground well. The suspension was filtered using a piece of cotton and filter paper. An excess of $0.1 \%$ SDS was added until the filtrate became clear. Ground tissue containing OBs was centrifuged at $6000 \mathrm{rpm}$ for $15 \mathrm{~min}$ at room temperature. The supernatant was discarded, and the pellet was resuspended in $1 \mathrm{ml} \mathrm{0.5 \%} \mathrm{SDS/larva} \mathrm{using} \mathrm{vortex} \mathrm{and} \mathrm{then} \mathrm{centrifuged}$ again at $6000 \mathrm{rpm}$ for $15 \mathrm{~min}$ at room temperature. The pellet was resuspended in $0.5 \mathrm{M} \mathrm{NaCl}$ by vortexing and then centrifuged again at $6000 \mathrm{rpm}$ for $15 \mathrm{~min}$. The pellet containing the purified virus was resuspended in a small volume of distilled $\mathrm{H}_{2} \mathrm{O}(0.5 \mathrm{ml} /$ larvae $)$ by gentle vortexing and kept frozen at $-20^{\circ} \mathrm{C}$ until use.

\section{Viral DNA extraction}

About $300 \mu \mathrm{l}$ purified virus OBs were precipitated for $15 \mathrm{~min}$ at $6000 \mathrm{rpm}$, the supernatant was discarded, and the pellet was resuspended in $200 \mu$ double-distilled $\mathrm{H}_{2} \mathrm{O}$. One molar of $\mathrm{Na}_{2} \mathrm{CO}_{3}$ at a final concentration of $0.1 \mathrm{M}$ was used and mixed by vortexing and then incubated for $1 \mathrm{~h}$ at $37^{\circ} \mathrm{C}$ in a water bath until the solution became clear. The solution was neutralized with $1 \mathrm{M}$ $\mathrm{HCl}$ to $\mathrm{pH} 8$, and $10 \%$ (w/w) SDS was added at a final concentration of $1 \%$. Proteinase $\mathrm{K}(50 \mu \mathrm{g} / \mathrm{ml})$ was added at a final concentration of $250 \mu \mathrm{g} / \mathrm{ml}$, and the mixture was vortexed and then incubated for $1 \mathrm{~h}$ at $37^{\circ} \mathrm{C}$. The probe was washed with TE saturated phenol/chloroform $(1: 1, \mathrm{v} / \mathrm{v})$, vortexed thoroughly, and spun down for $5 \mathrm{~min}$ at $14,000 \mathrm{rpm}$. The supernatant was collected in a new Eppendorf tube, and the sample was washed again with phenol mixture (phenol/chloroform 1:1, v/v) until there was no more white color between layers. The sample was washed twice with chloroform until the phenolic traces were removed. About 2.5 volumes of ice-cold $96 \%$ ethanol and 1/10 volume of $3 \mathrm{M} \mathrm{NaAc}$ ( $\mathrm{pH} 5.2$ ) were added to the sample, and genomic DNA was further precipitated for $30 \mathrm{~min}$ at $-80^{\circ} \mathrm{C}$ followed by centrifugation for $10 \mathrm{~min}$ at $14,000 \mathrm{rpm}$. The DNA pellet was washed twice with $70 \%$ ethanol and spun down for $10 \mathrm{~min}$ at $14,000 \mathrm{rpm}$ at room temperature. Viral genomic DNA was eluted overnight in $50 \mu \mathrm{l}$ autoclaved water at $4^{\circ} \mathrm{C}$.

\section{Amplification and sequence of chit $A$ gene}

One set of specific primers, ORF38EcoRI-F (5'-GACGGTACCATGTTAACGAAAAGTCATACAA- $3^{\prime}$ ) and ORF38XhoI-R (5'-GCCAAGCTTTTAATAATTCCGAATG ATG-3'), was designed and used to amplify the fulllength chitA gene using virus genomic DNA as a template. EcoRI and XhoI restriction sites were added to the 5 '-end of the forward and reverse primers, respectively, to facilitate the downstream cloning work. In a total volume of $50 \mu \mathrm{l}$, PCR was carried out. The PCR program started with an initial temperature of $95^{\circ} \mathrm{C}$ for $3 \mathrm{~min}$, a total of 35 cycles of denaturation at $95^{\circ} \mathrm{C}$ for $1 \mathrm{~min}$, annealing at $64^{\circ} \mathrm{C}$ for $1 \mathrm{~min}$, and extension at $72^{\circ} \mathrm{C}$ for $2 \mathrm{~min}$, in addition to a final cycle at $72^{\circ} \mathrm{C}$ for $7 \mathrm{~min}$. The PCR product was electrophoresed using agarose gel and purified using a QiaQuick PCR purification kit (Qiagen, Germany). The purified product was cloned into pLUGPrime TA-Cloning Vector (iNtRON Biotechnology) and transformed into Top10 competent cells. The purified plasmid was subjected to nucleotide sequencing using the Sanger method [25]. The partial nucleotide sequence of chitA was submitted to GenBank under accession number MN581943. A high-quality DNA sequence was used to predict amino acid sequence using an open reading frame (ORF) finder information database (https:// www.ncbi.nlm.nih.gov/), filtering BLAST results according to their accession number, and rendering them restricted to only referenced sequences. Multiple sequence alignment (MSA) was performed using Clustal Omega (https:/www.ebi.ac.uk/Tools/msa/clustalo/), Newick format, one of the outputs of Clustal Omega used to create a phylogenetic tree using IcyTree (https:/icytree.org).

\section{Cloning and expression of chit $A$ gene}

The chitA gene fragment was released from the demonstrated plasmid followed by subcloning into the pGEX-4T1 expression vector (Invitrogen). The clones harboring the chitA gene were verified and subsequently transformed into BL21 (DE3) Escherichia coli expression host. A bacterial colony containing the recombinant vector was cultured overnight with shaking at $37^{\circ} \mathrm{C}$. The 
next day, $10 \mathrm{ml}$ LB-broth medium with appropriate antibiotics was inoculated using $1 \mathrm{ml}$ of the overnight culture and shaken at $37^{\circ} \mathrm{C}(\sim 3 \mathrm{~h})$ until OD600 reached 0.6. ChitA protein expression was induced by adding IPTG at a final concentration of $1 \mathrm{mM}$, and bacteria were regrown overnight for $16 \mathrm{~h}$ at $17^{\circ} \mathrm{C}$. The culture $(1 \mathrm{ml})$ was collected in a time course at $0,1,2,3$, and overnight postinoculation, pelleted, and kept at $-20^{\circ} \mathrm{C}$ until use.

\section{Recombinant ChitA protein purification}

Spli-ChitA was expressed as a recombinant fusion protein with GST-tag located at pGEX-4T1, which was directly analyzed by SDS-polyacrylamide gel electrophoresis (PAGE), as described by Laemmli [26]. After the induction process for $16 \mathrm{~h}$ at $17^{\circ} \mathrm{C}$, bacterial culture $(1 \mathrm{~L})$ was harvested and lysed in $100 \mathrm{ml}$ lysis buffer $(50 \mathrm{mM}$ $\mathrm{NaH}_{2} \mathrm{PO}_{4}$ and $500 \mathrm{mM} \mathrm{NaCl}$ [pH 8]), followed by 10 times thawing and freezing in liquid nitrogen. Lysozyme was added at a final concentration of $1 \mathrm{mg} / \mathrm{ml}$ and incubated on ice for $30 \mathrm{~min}$. Triton X-100 was added from a $20 \%$ stock at a final concentration of $1 \times$, and the mixture was shaken for $30 \mathrm{~min}$, sonicated on ice at $40 \mathrm{amp}, 10 \mathrm{~s} /$ $10 \mathrm{~s}$ for $4 \mathrm{~min}$, and centrifuged for $20 \mathrm{~min}$ at $6000 \mathrm{rpm}$ at $4^{\circ} \mathrm{C}$. The prepared protein extract was added to the equilibrated resin and mixed on an end-over-end rotator for $60 \mathrm{~min}$ at $4{ }^{\circ} \mathrm{C}$. The mixture was centrifuged for $5 \mathrm{~min}$ at $6000 \mathrm{rpm}$, and the supernatant was discarded. The extracted protein was separated by SDS-PAGE (12\% gel) and subjected to western blot detection using antiGST monoclonal antibodies.

\section{Mice immunization and western blotting}

Whole-protein extract from the bacterial culture was separated based on their molecular mass using SDSPAGE, as described by Salem et al. [27], run on SDSPAGE, and transferred to polyvinylidene difluoride using a Semi-Dry Transfer Cell (Bio-Rad). The membrane was blocked in $2 \%$ fat-free milk at $4{ }^{\circ} \mathrm{C}$ overnight. Immunodetection was performed using the primary specific anti-GST monoclonal antibodies and the secondary antibody against mouse IgG conjugated with alkaline phosphatase. GST-fused Spli-ChitA detection was carried out using 5-Bromo-4-chloro-3-indolyl phosphate (BCIP) and nitro blue tetrazolium (NBT) substrates.

To generate IgG-specific polyclonal against ChitA expressed protein, the purified protein was injected into mice. Four female BALB/c mice (21 days old), obtained from the Research Institute of Ophthalmology, Egypt, were treated under the principles and policies of the National Institute of Health animal care. Mice were injected with the purified ChitA recombinant protein using the protocol described by Salem et al. [28]. The primary immune response was initiated by intraperitoneal injection of mice with $50 \mu \mathrm{g}$ ChitA protein emulsified in incomplete Freund's adjuvant, followed by four subsequent intravenous boosters, at weekly intervals, each with $100 \mu \mathrm{g}$ ChitA emulsified in incomplete Freund's adjuvant that was excluded from the last booster. Seven days after the fifth injection, sera were collected for the assessment of anti-ChitA seroconversion. Endogenous ChitA expression was analyzed by SDS-PAGE separation of cuticular proteins prepared from staged S. littoralis larvae guts, followed by western blotting analysis using the above raised anti-ChitA polyclonal antibodies.

\section{Transcriptional analysis of ChitA using quantitative RT- PCR (qRT-PCR)}

Total RNA was extracted from five pooled fourth instar S. littoralis larval midguts infected with SpliNPV using 50 to $100 \mathrm{mg}$ tissue at different time points $(12,24$, 48, 84, 96, 120, 148, and 168 hpi) using RNeasy Mini Kit (Qiagen). cDNA was synthesized from extracted mRNA of the infected $S$. littoralis larvae using RevertAid firststrand cDNA synthesis kit (Thermo Scientific, USA) according to the manufacturer's instructions. RT-PCR was performed in a final volume of $25 \mu \mathrm{l}$ reaction using the following components: EmeraldAmp GT PCR Master Mix ( $2 \times$ Premix; Takara Bio, Japan), $2 \mu \mathrm{l}$ cDNA, and $1 \mu \mathrm{l}$ of $10 \mathrm{pmol}$ of each gene-specific ChitA-DET-F as a forward primer 5'-ATAGAGGCGGATCGTTTAGTGC-3' and ChitA-DET-R as a reverse primer 5'-GCCGGTGCTGCGTCTCG-3'. The amplification condition was as follows: $94^{\circ} \mathrm{C}$ for $3 \mathrm{~min}, 35$ cycles of $94^{\circ} \mathrm{C}$ for $45 \mathrm{~s}, 58^{\circ} \mathrm{C}$ for $45 \mathrm{~s}$, and $72^{\circ} \mathrm{C} 1 \mathrm{~min}$, and finally $72^{\circ} \mathrm{C}$ for $7 \mathrm{~min}$. qRTPCR was performed in a final volume of $20 \mu \mathrm{l}$ reaction containing SYBR (Applied Biosystems, USA), cDNA, and gene-specific forward primer (ChitA-qRT-F) 5'TTGAGTGGGCCGACAGAAAT- $3^{\prime}$ and reverse primer (ChitA-qRT-R) 5'-AAACGTACGCCTCATCGCCTCCAC3'. The Spodoptera frugiperda ubiquitin gene was used as a housekeeping gene to normalize gene transcription data. The qPCR conditions were optimized as follows: 
$94^{\circ} \mathrm{C}$ for $10 \mathrm{~min}$, followed by 40 cycles of $95^{\circ} \mathrm{C}$ for $15 \mathrm{~s}$ and $60^{\circ} \mathrm{C}$ for $1 \mathrm{~min}$. The dissociation curve was determined by heating at $95^{\circ} \mathrm{C}$ for $60 \mathrm{~s}$, followed by $55^{\circ} \mathrm{C}$ for $30 \mathrm{~s}$ and $0.2^{\circ} \mathrm{C}$ increase per cycle until $95^{\circ} \mathrm{C}$. Three technical replicates were performed for each biological replicate. The relative gene transcription data were calculated using the $2^{-\Delta \Delta \mathrm{Ct}}$ method. $p<0.05$ was considered significantly different according to Duncan's post hoc test. The results are presented as the mean \pm standard error.

\section{Antifungal activity of recombinant ChitA protein}

The semipurified ChitA recombinant protein was assayed for antifungal activity against Fusarium oxysporum and Fusarium solani using the well diffusion assay on PDA plates (300 g/l potato extract, $20 \mathrm{~g} / \mathrm{l}$ dextrose, and $15 \mathrm{~g} / \mathrm{l}$ agar) [29]. A fungal plug (6 $\mathrm{mm}$ diameter) was removed from the 5-day old culture. The plug was transferred onto the center of the PDA plate loaded with different concentrations of the ChitA protein in two wells. The third well was loaded with the same volume of protein elution buffer, and the fourth well was loaded with the same amount of water as a negative control. The plates were incubated for 5 days at $28^{\circ} \mathrm{C}$ and subsequently monitored for the inhibition zone around the wells.

\section{Results}

\section{Sequencing and phylogenetic analysis of chit $A$ gene}

The chitA coding sequence was amplified from the genomic DNA of SpliNPV using two specific primers designed based on the published sequence of SpliNPV-

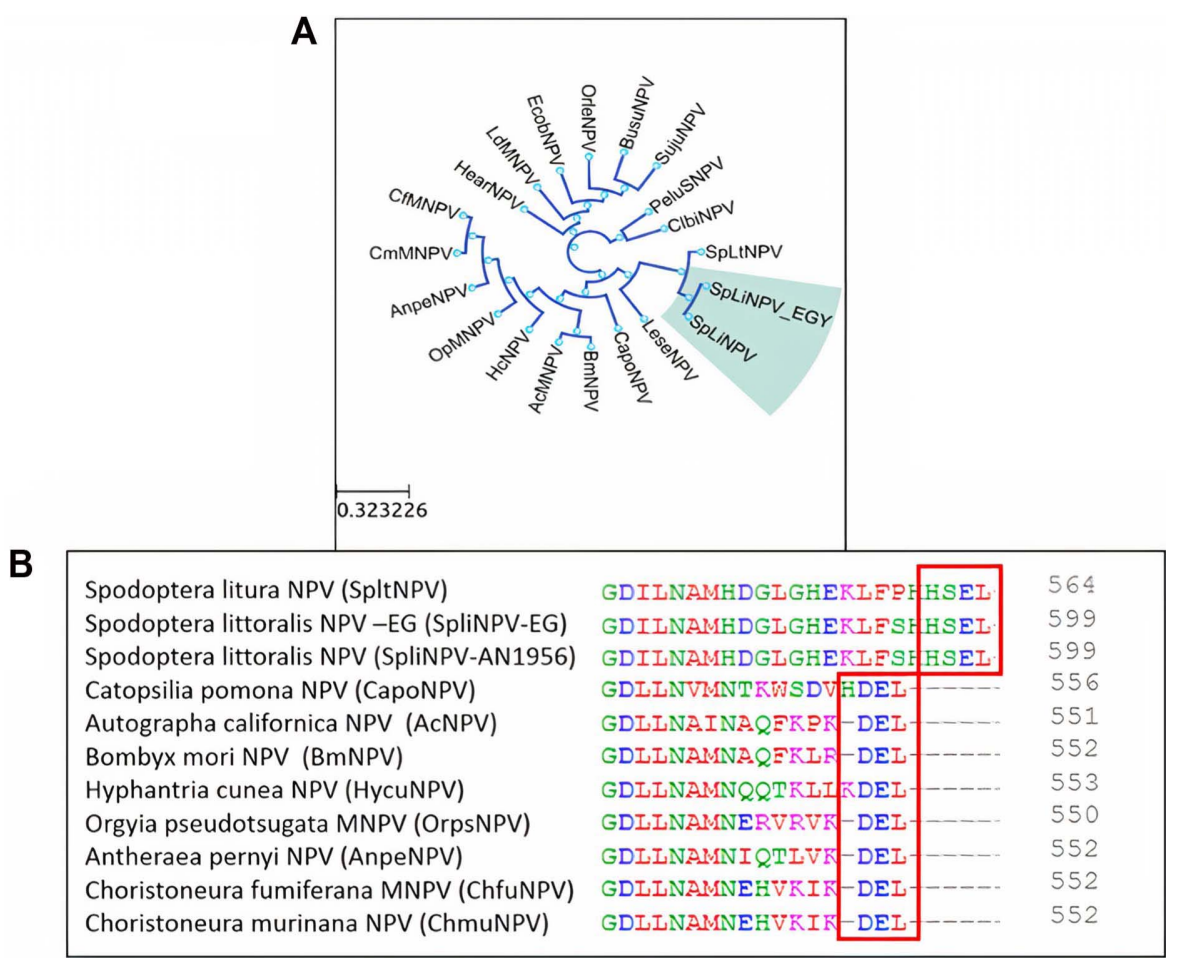

Fig. 1. Phylogenetic analysis of 19 chitinases genes from baculoviruses isolates located in GenBank. (A) Phylogenetic tree includes the NPV baculovirus isolates with their accession number as follow; Spodoptera littoralis NPV (YP_009505847.1), Spodoptera litura NPV (NP_258310.1), Perigonia lusca SNPV (YP_009165660.1), Leucania separata NPV (YP_758354.1), Orgyia leucostigma NPV (YP_001650934.1), Perigonia lusca SNPV (YP_009165660.1), Buzura suppressaria NPV (YP_009001828.1), Clanis bilineata NPV (YP_717597.1), Sucra jujuba NPV (YP_009186745.1), Hyphantria cunea NPV (YP_473218.1), Orgyia pseudotsugata MNPV (NP_046280.1), Lymantria dispar MNPV (NP_047707.1), [Helicoverpa armigera NPV (NP_203597.1), Autographa californica NPV (NP_054156.1), Bombyx mori NPV (NP_047523.1), Choristoneura fumiferana MNPV (NP_848428.1) Ectropis obliqua NPV(YP_874243.1), Catopsilia pomona NPV (YP_009255371.1), Antheraea pernyi NPV (YP_611002.1), and Choristoneura murinana NPV (YP_008992124.1). (B) The partial deduced amino acid sequence of ChitA of selected baculovirus isolates show the presence of a C-terminal of XXEL motif. Red frame shows similarly between baculovirus isolates in the C-terminal motifs of HSEL and XDEL. 
AN1956 (accession no. JX454574.1). The PCR amplicon with the expected fragment size of chitA $(1.8 \mathrm{~kb})$ and its identity were confirmed by nucleotide sequencing subsequently submitted to GenBank under accession number MN581943. Nucleotide sequence analysis revealed that chitA is composed of 1805 nucleotides encoding 601 amino acids. The MSA of the deduced amino acids was performed using Clustal Omega. Phylogenetic analyses showed that ChitA deduced amino acid sequence has different percentages similar to other baculovirus chitinases. As shown in Fig. 1A, MSA showed 99.33\% identity with SpliNPV (accession no. NC_038369.1), 99.29\% identity with Spodoptera litura NPV (accession no. NP_258310.1), 60.23\% identity with Bombyx mori NPV (accession no. NP_047523.1), 59.31\% identity with A. californica multiple NPV (accession no. NP_054156.1), and 58.38\% identity with Helicoverpa armigera multiple NPV (accession no. NP_203597.1). The MAS results in Newick format were used to construct the phylogenetic tree using the ETE Toolkit. In addition, the deduced amino acid sequence of ChitA showed the presence of a C-terminal HSEL motif (Fig. 1B). The amino acid alignment with the selected baculovirus chitinases showed the similarity of the C-terminal HSEL motif to both chitinases of SpliNPV-AN1956 and SpltNPV. Interestingly, the C-terminal of the KDEL motif was identified in other baculovirus chitinase sequences (e.g., CapoNPV, AcNPV, BmNPV, HycuNPV, OrpsNPV, AnpeNPV, ChfuNPV, and ChmuNPV; Fig. 1B).

\section{Transcription regulation of chit $A$ gene}

To examine the transcription and expression regulation of the chitA gene throughout the virus life cycle, RTPCR and qRT-PCR analyses were performed. Transcriptional analysis was performed using different time intervals of infected $S$. littoralis fourth instar larvae at 12, 24, 48, 84, 120, 144, and 168 hpi. As shown in Fig. 2A, chitA transcripts were first detected at $12 \mathrm{hpi}$, reached the
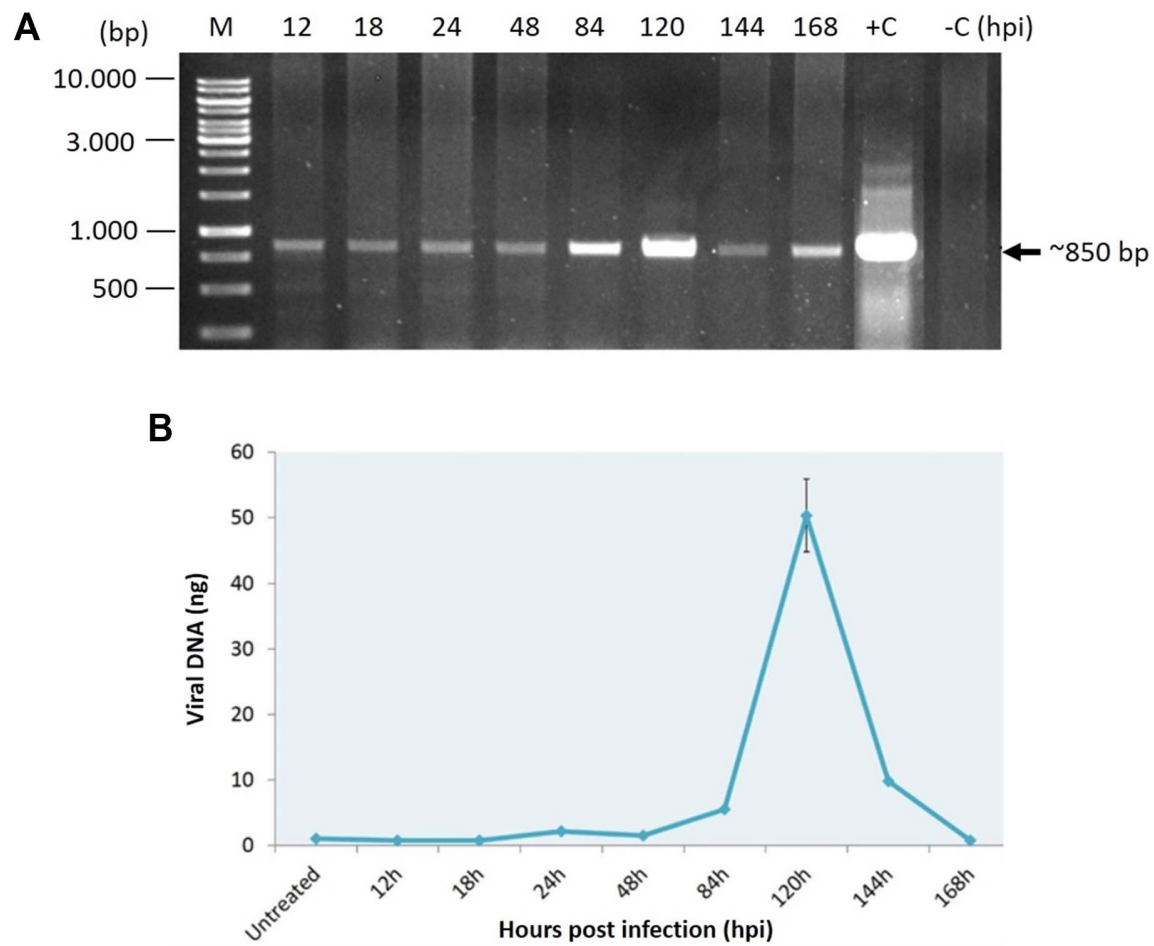

Fig. 2. (A) Gel electrophoresis of Spli-ChitA transcripts. The gel showing the transcrips of Spli-chitA gene at 12, 24, 48, 84, 120, 144 and $168 \mathrm{hpi}$. The gel shows a clear band at $850 \mathrm{bp}$ corresponding to chiA gene transcripts. The SpliNPV genomic DNA was used as a positive control (+ve control) and the negative control was used in which reverse transcriptase was omitted (-ve control). Lane $M$ corresponds to the $1 \mathrm{~kb}$ DNA standard marker. (B) Real-Time PCR quantitative analysis of the Spli-chitA transcripts. The line chart shows the quantitative analyses of chitA transcripts at different time points from $12 \mathrm{hpi}$ to $168 \mathrm{hpi}$ compared to untreated larvae. Error bars are located in each time point. 

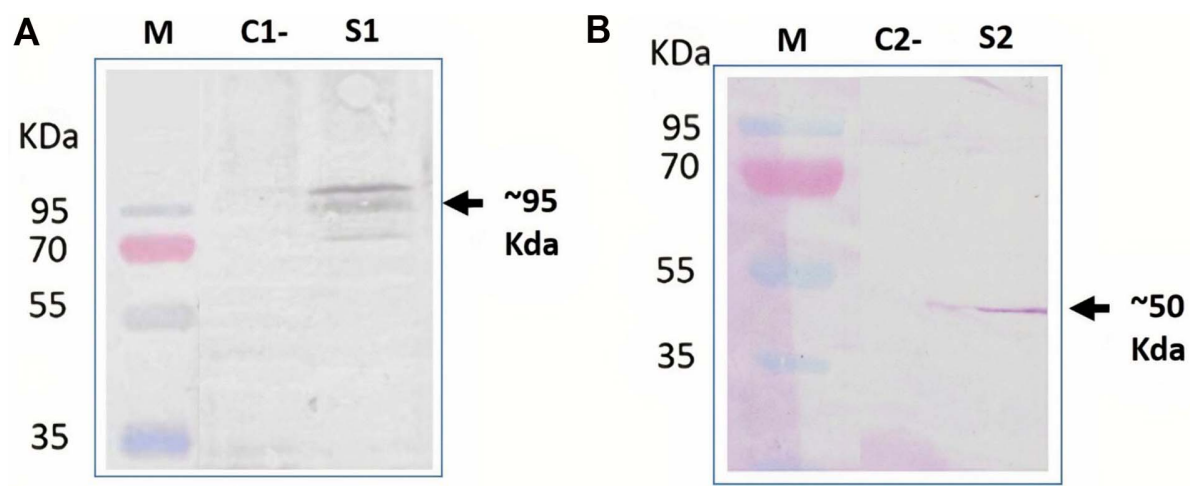

Fig. 3. Western blot analysis of ChitA immobilized on PVDF membrane. (A) Signals of ChitA protein detected using GST-tag monoclonal antibody. S1: Bacterial induced ChitA fused with GST-Tag. C1-: represent negative control (empty bacterial culture) (B) Membrane shows clear signals of ChitA protein detected by anti-SpliChitA polyclonal antibody. S2: ChitA in S. littoralis SpliNPVinfected larval tissue. C2-: corresponding to total protein extracted from midgut tissue from S. littoralis healthy larvae. M corresponds to the prestained protein standard marker. Protein molecular mass is given to the left by kilo Dalton (Kda).

peak at 120 hpi with high DNA fragment intensity, and remained detectable until 168 hpi. To substantiate the results obtained by RT-PCR, qRT-PCR was performed using cDNAs generated from the same RNA extracts used for RT-PCR. Quantified cDNAs were presented by the line graph in Fig. 2B. The results showed that a steady increase in the transcription levels of chitA was
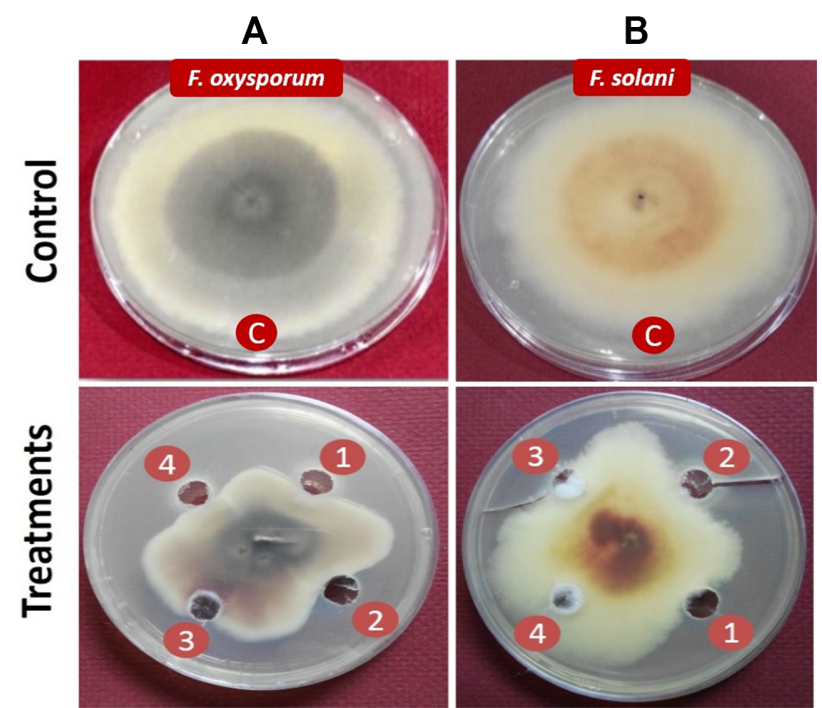

Fig. 4. Antifungal activity assay of ChitA protein towards (A) Fusarium Oxysporum (B) Fusarium solani. Each selected fungus was subjected to two different protein concentrations as well as two negative controls. (1) $100 \mathrm{mg} / \mathrm{ml}$, (2) $200 \mathrm{mg} / \mathrm{ml}$, (3) represent free pGEX4T1 empty vector in elution buffer, (4) represents distilled water. $(C)$ represent control plates for $S$. oxysporum and S. solani fungi. detected in SpliNPV-infected larvae, resulting in about a 7.8-fold increase at $84 \mathrm{hpi}$ up to a 71.4 -fold increase at $120 \mathrm{hpi}$, followed by dramatic decreases in transcription levels to 14 -fold at $144 \mathrm{hpi}$.

\section{Detection of ChitA protein by western blotting}

Western blotting analysis was performed to confirm the identity of the ChitA protein and its molecular weight. Using anti-GST monoclonal antibodies, western blotting was applied to the total proteins extracted from the overnight bacterial culture. As shown in Fig. 3A, monospecific antibodies of GST strongly responded to ChitA with a protein band of $\sim 93 \mathrm{kDa}$ corresponding to $26 \mathrm{kDa}$ plus $67 \mathrm{kDa}$ for GST and ChitA, respectively. To determine the native molecular mass of ChitA in $S$. littoralis larvae tissue, western blotting was performed in total protein extracted from midgut tissue of infected S. littoralis larvae. As shown in Fig. 3B, a protein band of about $\sim 50 \mathrm{kDa}$ was detected using an anti-ChitA polyclonal antibody previously generated against the purified ChitA protein.

\section{Antifungal activity of purified ChitA protein}

The enzymatic activity of the purified Spli-ChitA protein was examined using two phytopathogenic fungi: $F$. oxysporum and F. solani. As shown in Fig. 4, it exhibited a strong inhibitory effect on the mycelial growth of the subjected fungi. Significant growth retardation in the mycelia of $F$. oxysporum was observed at a concentration 
of $200 \mathrm{mg} / \mathrm{ml}$ of the purified chitinase protein, whereas the inhibition zone was lower around the wells where a concentration of $100 \mathrm{mg} / \mathrm{ml}$ of the purified protein was applied. No inhibitory effect was observed in control samples in which a free pGEX4T1 empty vector in protein elution buffer or a distilled water was used (Fig. 4A). In F. solani, less inhibition was observed at the $100 \mathrm{mg} / \mathrm{ml}$ concentration of the purified protein compared to other tested fungi, whereas a clear zone of inhibition at a concentration of $200 \mathrm{mg} / \mathrm{ml}$ can be seen compared to the negative controls (Fig. 4B).

\section{Discussion}

Among insect viruses found in nature, those belonging to the baculovirus family (Baculoviridae) were considered for the development of most commercial viral biopesticides. Upon infection, chitinase enzymes of baculoviruses are responsible for chitin degradation of the insect host that has a vital role during insect growth and development. Chitinases are a group of enzymes that degrade chitin. Chitin and chitinolytic enzymes have a highly important role in agricultural applications, especially for controlling pathogens. In this study, chitA from SpliNPV-EG1, an Egyptian isolate, was characterized. ChitA is a protein that promotes the final liquefaction of infected larvae [30]. The first baculovirus chitinase was previously reported from AcNPV infecting the alfalfa looper [17]. The functional characterization of SpliNPV chitinase is critical as few reports are available from Alphabaculovirus [17]. The ORF of the chitA gene contains $1805 \mathrm{bp}$ and encodes a protein of 601 amino acids with a predicted molecular weight of $\sim 67 \mathrm{kDa}$. Phylogenetic analysis using the deduced amino acid sequence of SpliNPV chitinase showed different similarity percentages to other reported baculovirus chitinases in GenBank to date. The highest identity was 99.33\% with SpliNPVAN1956 (accession no. NC_038369), and the lowest identity was $59.31 \%$ with chitinase of AcNPV (accession no. NP_054156.1). Wang et al. [31] reported that AcNPV chitinase is closely related to chitinase of $S$. marcescens bacteria, suggesting a horizontal gene transfer from $S$. marcescens to baculoviruses. S. marcescens is an enteric pathogen of a wide diversity of animals and is regularly found in the insect gut. Baculoviruses replicate their genome within the host nucleus, and $S$. marcescens can attack the cavity of the insect body through midgut cells. A baculovirus and a Serratia-like entomopathogenic bacterium may have contact with the host's DNA, subsequently leading to DNA fragment exchange [32].

chitA has been classified as a member of glycosyl hydrolase family 18 due to the presence of two family 18 conserved motifs, SIGG and FDGVDIDWE, as conserved regions. All insect chitinases reported so far have been classified to glycosyl hydrolase family 18 [33]. This family includes several chitinase-related proteins that lack the active-site glutamate residue. The deduced amino acid sequence of Spli-ChitA showed the presence of a C-terminal HSEL motif. These data agreed with the earlier findings in most baculoviruses for the presence of a C-terminal KDEL motif $[34,35]$ or its variants (XXEL), such as RDEL [36], HNEL [37], and KTEL [38], which plays a significant role in the retention and stability of the enzyme within endoplasmic reticulum vesicles [39]. The accumulated data revealed that the KDEL motif is a significant determinant for the secretion of viral chitinases.

Transcription analysis of Spli-ChitA mRNA was carried out in a stage- and tissue-specific manner by RTPCR and quantified by qRT-PCR. Transcriptional analysis was applied using different time points of fourth instars at $12,24,48,84,120,144$, and 168 hpi. Spli-chitA transcripts were first detected at $12 \mathrm{hpi}$, reached the peak at $120 \mathrm{hpi}$, and remained detectable until $168 \mathrm{hpi}$. These observations suggested that chitA is transcribed at the late phase of viral infection, consistent with the presence of a late promoter motif (ATAAG) located within 100 nucleotides upstream from the first ATG start codon. These data also confirmed earlier findings that chitinase is a late baculovirus gene product as recorded in the AcNPV genome [17]. qRT-PCR showed a steady increase in the transcription amount of chitA from 12 to $120 \mathrm{hpi}$, resulting in a 7.5-fold increase at $84 \mathrm{hpi}$ up to a 71 -fold at $120 \mathrm{hpi}$. qRT-PCR demonstrated that the expression of the transcripts reached a maximum at 4 to 5 days postinfection, with a significant decrease toward the later period of infection. In insects, chitinase expressed in the ecdysis gland specifically regulates insect growth [40]. Its transcription in the midgut has a digestive purpose and degrades the chitin of the PM [41]. mRNA expression of chitinase increased significantly 
before each molting and decreased rapidly after each molting, most likely due to the occurrence or lack of ecdysteroids [42]. RNA interference experiments in Tribolium castaneum showed that some chitinase genes undertook redundant functions other than molting [43]. Takahashi et al. [44] reported that, in the fourth instar, B. mori chitinase (BmChiR1) mRNA was induced on the third day, at the ecdysteroid peak, and decreased to basal levels on day 3.5. In the fifth instar, BmChiR1 mRNA was rarely detected during spinning periods and feeding [44]. Alternatively, some chitinases were needed under particular conditions, such as digestion or innate immunity [45].

Western blotting using the anti-SpliNPV chitinase antibody identified a protein of about $50 \mathrm{kDa}$ corresponding to the mature chitinase of SpliNPV. This was in accordance with $\mathrm{Oh}$ et al. [46], who characterized the chitinase gene from Pieris rapae GV. They demonstrated that SDS-PAGE and western blotting identified a protein of $72 \mathrm{kDa}$ with an $\mathrm{N}$-terminal leader sequence that might be cleaved after the putative 18-amino acid-long signal peptide sequence to generate a mature protein of $70 \mathrm{kDa}$. However, the size of chitA is not consistent with the predicted size of the mature protein of $66 \mathrm{kDa}$ based on the published sequence, suggesting that degradation of the mature protein may happen due to protein instability because of high protease activity that decreased the protein's molecular weight. To examine the effects of ChitA protein on phytopathogenic fungi, its inhibitory effect on fungal growth was determined. Recombinant ChitA expressed in $E$. coli showed in vitro inhibitory activity toward the growth of two fungi species, $F$. solani and $F$. oxysporum, on PDA plates at $28^{\circ} \mathrm{C}$ with clear zones surrounding the growth area of Fusarium spp. in all treated plates. These observations suggested the correct assembly and activity of the purified ChitA protein.

Earlier studies of some Fusarium spp. have revealed that the main polysaccharides found in these walls were chitin and $\beta$-glucan. The fungal cell wall comprises the following components: glucuronic acid, glucose, galactose, $\mathrm{N}$-acetylglucosamine, mannose, and proteins [47]. Other studies suggested that the antifungal activities of chitinase family 18 were not that effective; however, Chi18bA relatively inhibited the growth of Trichoderma viride, Mucorjavaniccus, and Trichoderma reesei [48].
The antifungal potential of chitinases depends mainly on the morphology of the complex fungal cell walls. This revealed that chitin is constructed in the cell wall in such a way that can simply be exposed to chitinases. However, in chitinase-resistant fungal species, the chitin layer is not always exposed to chitinases.

In conclusion, this work highlights SpliNPV chitinase by its molecular characterization and transcriptional and expression regulation and its activity against two common soil fungal species. Together with its effects on pathogenic fungi, these features indicate that this protein could be included in biocontrol studies in addition to fungi and insect pest industrial formulations for sustainable agricultural biocontrol applications.

\section{Conflict of Interest}

The authors have no financial conflicts of interest to declare.

\section{References}

1. Kumar B. 2016. Biocontrol of insect pests (Ch.2). pp. 25-61. In: Ecofriendly pest management for food security (Editor: Omkar). Academic Press, India.

2. van Oers MM, Pijlman GP, Vlak JM. 2015. Thirty years of baculovirusinsect cell protein expression: From dark horse to mainstream technology. J. Gen. Virol. 96: 6-23.

3. Elgaied L, Salem R, Elmenofy W. 2017. Expression of tomato yellow leaf curl virus coat protein using baculovirus expression system and evaluation of its utility as a viral antigen. 3 Biotech. 7: 269.

4. Elmenofy W, Mohamed I, El-Gaied L, Salem R, Osman G, Ibrahim M. 2020. Expression of $1 \mathrm{~B}$ capsid protein of Foot-and-mouth disease virus (FMDV) using baculovirus expression system and its validation in detecting SAT 2- specific antisera. Peer J. 8: e8946.

5. Theilmann DA, Blissard GW, Bonning B, Jehle J, O'Reilly DR, Rohrmann GF, et al. 2005. "Baculoviridae" Eighth report of the international committee on taxonomy of viruses. pp. 177-185. Van Regenmortel HV, Bishop DHL, Van Regenmortel MH, Fauquet CM (eds.), Elsevier Academic Press, New York, USA.

6. El-Menofy W, Osman G, Assaeedi A, Salama M. 2014. A novel recombinant baculovirus overexpressing a Bacillus thuringiensis Cry1Ab toxin enhances insecticidal activity. Biol. Proced. Online 16: 7.

7. Elmenofy WH, Jehle AJ. 2015. Possible functional co-operation of palindromes $\mathrm{hr} 3$ and $\mathrm{hr} 4$ in the genome of Cydia pomonella granulovirus affects viral replication capacity. J. Gen. Virol. 96: 2888-22897.

8. Abdallah NA, El-Menofy W, Abdelhadi AA. 2017. Designing of a recombinant Agip-bacmid construct with infectious properties 
against black cutworm Agrotis ipsilon larvae. Appl. Biochem. Biotechnol. 183: 307-317.

9. Moscardi F. 1999. Assessment of the application of baculoviruses for control of Lepidoptera. Annu. Rev. Entomol. 44: 257-289.

10. Tharanathan RN, Kittur FS. 2003. Chitin-The undisputed biomolecule of great potential. Crit. Rev. Food Sci. Nutr. 43: 61-87.

11. Kasprzewska A. 2003. Plant chitinases-regulation and function. Cell Mol. Biol. Lett. 8: 809-824.

12. Merzendorfer H, Zimoch L. 2003. Chitin metabolism in insects: structure, function and regulation of chitin synthases and chitinases. J. Exp. Biol. 206: 4393-4412.

13. Thomas CJ, Gooday GW, King LA, Possee RD. 2000. Mutagenesis of the active site coding region of the Autographa californica nucleopolyhedrovirus chiA gene. J. Gen. Virol. 81: 1403-1411.

14. Hawtin RE, Zarkowska T, Arnold K, Thomas CJ, Gooday GW, King LA, et al. 1997. Liquefaction of Autographa californica nucleopolyhedrovirus-infected insects is dependent on the integrity of virus-encoded chitinase and cathepsin genes. Virology 238: 243253.

15. Hughes AL, Friedman R. 2003. Genome-wide survey for genes horizontally transferred from cellular organisms to baculoviruses. Mol. Biol. Evol. 20: 979-987.

16. Kang W, Tristem M, Maeda S, Crook NE, O'Reilly DR. 1998. Identification and characterization of the Cydia pomonella granulovirus cathepsin and chitinase genes. J. Gen. Virol. 79: 2283-2292.

17. Hawtin RE, Arnold K, Ayres MD, Zanotto PM, Howard SC, Gooday GW, et al. 1995. Identification and preliminary characterization of a chitinase gene in the Autographa californica nuclear polyhedrosis virus genome. Virology 212: 673-685.

18. Daimon T, Katsuma S, Kang W, Shimada T. 2006. Comparative studies of Bombyx mori nucleopolyhedrovirus chitinase and its host ortholog, BmChi-h. Biochem. Biophys. Res. Commun. 345 825-833.

19. Saville GP, Thomas CJ, Possee RD, King LA. 2002. Partial redistribution of the Autographa californica nucleopolyhedrovirus chitinase in virus-infected cells accompanies mutation of the carboxy-terminal KDEL ER-retention motif. J. Gen. Virol. 83: 685694.

20. Saville GP, Patmanidi AL, Possee RD, King LA. 2004. Deletion of the Autographa californica nucleopolyhedrovirus chitinase KDEL motif and in vitro and in vivo analysis of the modified virus. J. Gen. Virol. 85: 821-831.

21. Seufi AM. 2008. Characterization of an Egyptian Spodoptera littoralis nucleopolyhedrovirus and a possible use of a highly conserved region from polyhedrin gene for nucleopolyhedrovirus detection. Virol. J. 5: 13.

22. Atia MA, Osman GH, Elmenofy WH. 2016. Genome-wide in silico analysis, characterization and identification of microsatellites in Spodoptera littoralis multiple nucleopolyhedrovirus (SpliMNPV). Sci. Rep. 6: 33741.

23. Breitenbacha JE, El-Sheikha A, Harrison RB, Rowleyb DL, Sparksb ME, Gundersen-Rindalb DE, et al. 2013. Determination and analysis of the genome sequence of Spodoptera littoralis multiple nuc- leopolyhedrovirus. Virus Res. 171: 194-208.

24. Ivaldi-Sender C. 1974. Techniques simples pour elevage permanent de la tordeuse orientale, Grapholita molesta (Lep., Tortricdae), sur milieu artificiel. Ann. Zoo Ecol. Anim. 6: 337-343.

25. Sanger F, Nicklen S, Coulson AR. 1977. DNA sequencing with chain-terminating inhibitors. Proc. Natl. Acad. Sci. USA 74: 54635467.

26. Laemmli UK. 1970. Cleavage of structural proteins during the assembly of the head of bacteriophage T4. Nature 227: 680-685.

27. Salem R, Assem KS, Omar AO, Khalil AA, Basry AM, Waly RF, et al. 2020. Expressing the immunodominant projection domain of infectious bursal disease virus fused to the fragment crystallizable of chicken IgY in yellow maize for a prospective edible vaccine. Mol. Immunol. 118C: 132-141.

28. Salem R, El-Kholy AA, Ibrahim M. 2019. Eight novel single chain antibody fragments recognizing VP2 of foot-and-mouth disease virus serotypes A, O, and SAT 2. Virology 533: 145-154.

29. Salmaninezhad F, Mostowfizadeh-Ghalamfarsa R. 2019. Three new pythium species from rice paddy fields. Mycologia 111: 274290.

30. Vaaje-Kolstad G, Douglas RH, Francesco VR, Martin GP, Bjørnar S, Daan MF, et al. 2004. Structure of the D142N mutant of the family 18 chitinase ChiB from Serratia marcescens and its complex with allosamidin. Biochim. Biophys. Acta 1696: 103-111.

31. Wang $\mathrm{H}$, Wu D, Deng F, Peng $\mathrm{H}$, Chen $\mathrm{X}$, Lauzon $\mathrm{H}$, et al. 2004. Characterization and phylogenetic analysis of the chitinase gene from the Helicoverpa armigera single nucleocapsid nucleopolyhedrovirus. Virus Res. 100: 179-189.

32. Fang $M$, Wang $H$, Wang $H$, Yuan L, Chen X, Vlak JM, et al. 2003. Open reading frame 94 of Helicoverpa armigera single nucleocapsid nucleopolyhedrovirus encodes a novel conserved occlusion-derived virion protein, ODV-EC43. J. Gen. Virol. 84: 30213027.

33. He L, Yu H, Xu CY, Zhao Y, Yang FX, Guo YD, et al. 2019. Molecular characterization, activity analysis and transcriptional detection of chitinases encoded in the genome of Spodoptera exigua. J. ASIA-PAC Entomol. 22: 499-505.

34. Ahrens $\mathrm{CH}$, Russell RL, Funk CJ, Evans JT, Harwood SH, Rohrmann GF. 1997. The sequence of the Orgyia pseudosugata multi nucleocapsid nuclear polyhedrosis virus genome. Virology 229: 381399.

35. Ayres MD, Howard SC, Kuzio J, Lopez-Ferber M, Possee RD. 1994. The complete DNA sequence of Autographa californica nuclear polyhedrosis virus. Virology 202: 586-605.

36. Hyink O, Dellow RA, Olsen MJ, Caradoc-Davies KM, Drake K, Herniou EA, et al. 2002. Whole genome analysis of the Epiphyas postvittana nucleopolyhedrovirus. J. Gen. Virol. 83: 957-971.

37. Chen X, ljkel WF, Tarchini R, Sun $X$, Sandbrink H, Wang $H$, et al. 2001. The sequence of the Helicoverpa armigera single nucleocapsids nucleopolyhedrovirus genome. J. Gen. Virol. 82: 241-257.

38. Li Q, Donly C, Li L, Willis LG, Theilmann DA, Erlandson M. 2002. Sequence and organization of the Mamestra configurate nucleopolyhedrovirus genome. Virology 294: 106-121. 
39. Frigerio L, Pastres A, Prada A, Vitale A. 2001. Influence of KDEL on the fate of trimeric or assembly-defective phaseolin: Selective use of an alternative route to vacuoles. Plant Cell 13: 1109-1126.

40. Stuart E, Reynolds, Richard I, Samuels. 1996. Physiology and biochemistry of insect moulting fluid. Adv. Insect Physiol. 26: 157232.

41. Filho BP, Lemos FJ, Secundino NF, Páscoa V, Pereira ST, Pimenta PF. 2002. Presence of chitinase and beta- $N$-acetylglucosaminidase in the Aedes aegypti: a chitinolytic system involving peritrophic matrix formation and degradation. Insect Biochem. Mol. Biol. 32: 1723-1729.

42. Zhang D, Chen J, Yao Q, Pan Z, Chenet J, Zhang W. 2012. Functional analysis of two chitinase genes during the pupation and eclosion stages of the beet armyworm Spodoptera exigua by RNA interference. Arch Insect Biochem. 79: 220-234.

43. Zhu Q, Arakane Y, Beeman RW, Kramer KJ, Muthukrishnan S. 2008. Functional specialization among insect Chitinase family genes revealed by RNA interference. PNAS 105: 6650-6655.
44. Takahashi M, Kiuchi M, Kamimura M. 2002. A new chitinaserelated gene, BmChiR1, is induced in the Bombyx mori anterior silk gland at molt and metamorphosis by ecdysteroid. Insect Biochem. Mol. Biol. 32: 147-151.

45. Xu H, He L, Xiao W, Shen G. 2017. Identification of the key chitinase genes in Tetranychus cinnabarinus (Boisduval) based on the expression and sequence characteristic analysis. J. Integr. Agric. 16: 892-899.

46. Oh S, Kim DH, Bharat BP, Patnaik BB, Jo YH, Noh MY, et al. 2013. Molecular and immunohistochemical characterization of the chitinase gene from Pieris rapae granulovirus. Arch. Virol. 158: 1701-1718.

47. Schoffelmeer EA, Klis FM, Sietsma JH, Cornelissen BJ. 1999. The cell wall of Fusarium oxysporum. Fungal Genet. Biol. 27: 275-282.

48. Kawase T, Yokokawa S, Saito A, Fujii T, Nikaidouet N, Miyashita K, et al. 2006. Comparison of enzymatic and antifungal properties between family 18 and 19 chitinases from S. coelicolor A3(2). Biosci. Biotechnol. Biochem. 70: 988-998. 